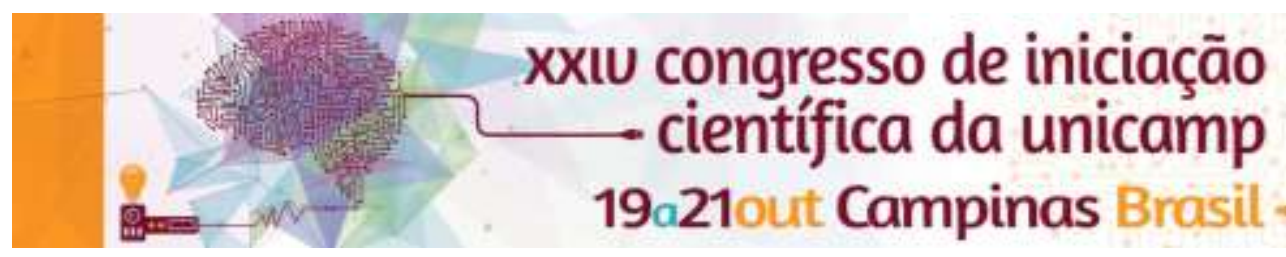

\title{
Avaliação de preparo de amostras de urina para análise de compostos orgânicos voláteis por GC-MS para estudo de perfil metabolômico: estudos iniciais.
}

\author{
Natália A. M. Paulo*, Felipe M. Aggio, José Luiz P. Jara, Marcos N. Eberlin, Ana Valéria C. Simionato.
}

\section{Resumo}

Para que uma análise cromatográfica do perfil metabolômico de um fluido biológico seja abrangente, é necessário otimizar as diversas variáveis envolvidas, de forma que seja possível detectar a maior quantidade de picos possíveis. Este trabalho apresenta as etapas iniciais de otimização da extração de compostos orgânicos voláteis (VOCs) de urina por microextração em fase sólida-headspace (SPME-HS) seguida por análise por cromatografia gasosa acoplada a espectrômetro de massas (GC-MS).

\section{Palavras-chave}

Metabolômica, compostos orgânicos voláteis, GC-MS.

\section{Introdução}

Uma das abordagens metabolômicas mais promissoras é a análise de compostos orgânicos voláteis (chamados de VOCs, sigla em inglês), que podem servir como potenciais biomarcadores usados em testes seguros, não invasivos e específicos, para a detecção precoce de diferentes tipos doenças, como o câncer. Tais VOCs podem ser extraídos de fluidos biológicos como a urina, entretanto, para que se obtenha um resultado que seja o mais coerente possível com a real composição da amostra, é preciso que seja realizada uma otimização de diversos componentes do procedimento experimental, visando a obtenção da maior quantidade de picos bem resolvidos no cromatograma alvo. A otimização consiste, também, na escolha do método, sendo que, idealmente, um método de preparo de amostras deve ser simples, apresentar alta capacidade e seletividade de extração, ser eficiente, rápido, potencialmente automatizado e compatível com o método de análise, seguro para o operador e para o meio ambiente. A microextração em fase sólida (SPME) é uma técnica que integra a extração, a concentração e a introdução da amostra no cromatógrafo a gás em apenas uma etapa e seu uso resulta na redução do tempo de preparo da amostra e aumento da sensibilidade, em relação a outros métodos de extração, sendo um método eficiente para amostragem de VOCs, devido às complicadas características biológicas destes compostos.

\section{Resultados e Discussão}

As amostragens foram realizadas por SPME-HS com fibra 80/30 $\mu \mathrm{m}$ DVB/CARP/PDMS Stableflex seguido de análise por GC-MS em um equipamento Agilent Technologies $5975 \mathrm{C}$ com coluna HP $-5 \mathrm{MS}$ de $30 \mathrm{~m} \times$ $0,250 \mathrm{~mm} \times 0,25 \mu \mathrm{m}$. Para a otimização do preparo de amostra foi realizado um planejamento com as 3 variáveis em questão, de forma a otimizá-las concomitantemente (Tabela 1), visando a obtenção do maior número de picos cromatográficos. As condições que apresentaram os melhores resultados são destacadas na Tabela 1 e resultaram em um cromatogramas com 83 picos (Figura 1).

Tabela 1. Planejamento experimental $2^{3}$ do preparo de amostra de urina por SPME-HS $(n=3)$. Parâmetros avaliados: $[\mathrm{NaCl}](\% \mathrm{~m} / \mathrm{v}):(+)=40,(-)=30$; tempo de exposição da fibra no vial: $(+)=30,(-)=15$; temperatura de incubação do vial $\left({ }^{\circ} \mathrm{C}\right):(+)=40,(-)=30$.

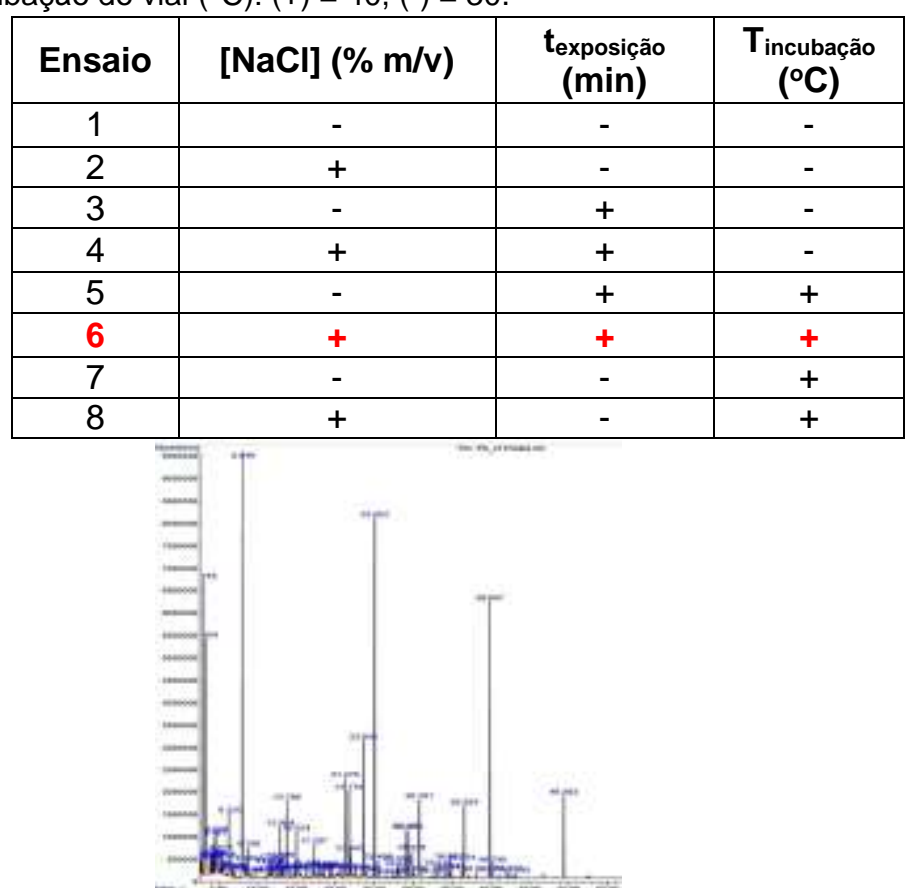

Figura 1. Cromatograma obtido na condição otimizada.

Segundo o Human Metabolome Database ${ }^{2}$, alguns metabólitos foram identificados, como a 4-Heptanona (8.049 min) e Manitol (40.230 min).

\section{Conclusões}

As condições de extração que propiciaram o maior número de picos cromatográficos são adição de $40 \%$ $\mathrm{NaCl}$ à amostra e $30 \mathrm{~min}$ de exposição da fibra ao headspace à $40^{\circ} \mathrm{C}(+,+,+)$. Esses resultados indicam que maiores valores de cada variável deverão ser avaliados em uma nova otimização para verificar se maior número de compostos pode ser detectado. Pretende-se futuramente aplicar o método otimizado para comparar o perfil metabolômico de VOCs de indivíduos sadios com o de indivíduos com linfoma não-Hodgkin.

\section{Agradecimentos}

Ao Hemocentro da Unicamp e ao Laboratório de Bioquímica do Exercício. À FAPESP CAPES e CNPq.

\footnotetext{
1 Zhang, Z., Microchemical J., 2010, 95, 127-139.
}

${ }^{2}$ http://www.hmdb.ca/ (acesso em 14/07/16 às 16:00) 